\title{
Treatment of angina pectoris with nifedipine: a double blind comparison of nifedipine and slow-release nifedipine alone and in combination with atenolol
}

\author{
T CRAKE, A A QUYYUMI, C WRIGHT, L MOCKUS, K M FOX \\ From the National Heart Hospital, London
}

SUMMARY The relative efficacy of nifedipine and slow-release nifedipine (Adalat Retard) in the treatment of stable exertional angina pectoris was evaluated in a double blind randomised crossover study in eight patients on no concomitant antianginal treatment and in 10 patients who were additionally on atenolol. Patients were assessed by angina diaries and exercise testing. Slowrelease nifedipine was as effective as nifedipine in the treatment of these patients, both alone and in combination with atenolol.

Nifedipine is well established in the treatment of stable exertional angina pectoris both alone ${ }^{1}$ and in combination with $\beta$ receptor antagonists. ${ }^{2}$ A slowrelease nifedipine preparation ( $20 \mathrm{mg}$ tablets) is now available for the treatment of hypertension and twice daily administration of this preparation is as effective as a daily dose of $30 \mathrm{mg}$ (one $10 \mathrm{mg}$ capsule three times a day) of the short acting preparation. ${ }^{3}$ This is clearly more convenient for the patient and it may also avoid the high peak post-dose concentrations of nifedipine which may contribute to side effects ${ }^{4}$ and limit its usefulness. Slow-release nifedipine (Adalat Retard) is therefore being increasingly prescribed for the treatment of exertional angina despite any evidence to show that it is effective in this situation. In this study we have compared the two preparations of nifedipine both alone and in combination with a $\beta$ receptor antagonist in the treatment of stable exertional angina.

\section{Patients and methods}

We studied two groups of patients. All were normotensive and had stable ( $>3$ months) exertional angina pectoris. All had important atheromatous coronary artery disease demonstrated on coronary

Requests for reprints to Dr T Crake, National Heart Hospital, Westmoreland Street, London W1M 8BA.

Accepted for publication 7 July 1987 arteriography. None had suffered a myocardial infarction within the previous year, none had heart failure or respiratory disease, and none was taking digoxin or antiarrhythmic agents. Group 1 consisted of eight patients (seven men and one woman, mean (SEM) age 58 (7) years) and group 2 consisted of 10 patients (nine men and one woman, mean (SEM) age 54 (6) years). Group 1 patients were on no other treatment whereas group 2 patients were taking a $\beta_{1}$ receptor antagonist (atenolol $100 \mathrm{mg}$ daily). Before entering the study all had chest pain and significant ST segment depression on treadmill exercise testing. Significant ST segment depression was defined as planar or downsloping depression of $>1 \mathrm{~mm}$ occurring 0.08 seconds after the J point. The study consisted of a two week single blind placebo run in period followed by two treatment phases each lasting two weeks during which the patients received either nifedipine or slow-release nifedipine in a double blind randomised crossover manner. Nifedipine was given in a dose of $10 \mathrm{mg}$ three times daily for the first three days and then $20 \mathrm{mg}$ three times daily for the remainder of that phase to avoid the problems that occasionally arise from administering the higher dose. ${ }^{1}$ For the same reason slow-release nifedipine was started in a dose of $20 \mathrm{mg}$ twice daily for three days and thereafter increased to $40 \mathrm{mg}$ twice daily. Throughout the study patients were encouraged to undertake their normal activities and used sublingual nitroglycerin for pain relief. 
To assess the effects of treatment we used the angina diaries that the patients kept throughout the placebo run in period and the two treatment periods and the maximum symptom limited treadmill exercise tests that they performed at the end of each two week period. A standard 12 lead electrocardiogram was recorded before and at one minute intervals during exercise together with heart rate and blood pressure. Exercise tests were terminated by severe chest pain, hypotension, arrhythmias, exhaustion, and when $>3 \mathrm{~mm}$ ST segment depression occurred with or without pain. The duration of exercise to chest pain, $1 \mathrm{~mm}$ ST segment depression, and maximum exercise were noted.

Results are expressed as mean (SEM) and data were compared by Student's $t$ test for paired observations.

\section{Results}

GROUP 1: NIFEDIPINE VERSUS SLOW-RELEASE

NIFEDIPINE ALONE

Angina frequency was similar during the placebo period and during the two treatment phases of the study (table 1). No patient reported symptomatic deterioration with either nifedipine preparation. Heart rate and rate pressure product at rest and at $1 \mathrm{~mm}$ ST segment depression were similar with the two preparations of nifedipine (table 2). Exercise duration to pain and to $1 \mathrm{~mm}$ ST segment depression and maximum exercise duration were significantly prolonged by both nifedipine and slowrelease nifedipine compared with the placebo but there was no difference between either preparation (table 1 and figure). Responses to the two preparations varied: in three patients exercise duration to $1 \mathrm{~mm}$ ST segment depression was greater with slowrelease nifedipine than with nifedipine, in four it was similar, and in one patient it was greater with nifedipine than with slow-release nifedipine (figure).

GROUP 2: NIFEDIPINE VERSUS SLOW-RELEASE NIFEDIPINE IN COMBINATION WITH ATENOLOL Results were similar in this group of patients. Angina frequency tended to be less during treatment with slow-release nifedipine than with nifedipine

Table 1 Angina frequency and duration of treadmill exercise to $1 \mathrm{~mm} S T$ segment depression, to chest pain, and to the termination of the test in both patient groups during the placebo run in period and the two treatment phases of the study (mean (SEM))

\begin{tabular}{|c|c|c|c|c|}
\hline & \multirow[b]{2}{*}{$\begin{array}{l}\text { Angina frequency } \\
\text { (episodes/week) }\end{array}$} & \multicolumn{3}{|c|}{ Duration of exercise (min) to: } \\
\hline & & $\begin{array}{l}1 \mathrm{~mm} S T \\
\text { segment depression }\end{array}$ & Chest pain & $\begin{array}{l}\text { Termination } \\
\text { of test }\end{array}$ \\
\hline $\begin{array}{l}\text { Group } 1 \\
\text { Placebo } \\
\text { Nifedipine } \\
\text { Slow-release nifedipine }\end{array}$ & $\begin{array}{l}6 \cdot 1(3 \cdot 5) \\
5 \cdot 5(4 \cdot 0) \\
5 \cdot 3(4 \cdot 0)\end{array}$ & $\begin{array}{l}4.5(0.8) \\
5 \cdot 8(0.9)^{\star} \\
6.3(1 \cdot 1)^{\star}\end{array}$ & $\begin{array}{l}6.0(0.9) \\
8.9(0.9)^{\star} \\
7.8(0.9)^{\star}\end{array}$ & $\begin{array}{l}6.9(0.7) \\
9.4(0.6)^{\star} \\
8.7(0.8)^{\star}\end{array}$ \\
\hline $\begin{array}{l}\text { Group } 2 \\
\text { Placebo } \\
\text { Nifedipine } \\
\text { Slow-release nifedipine }\end{array}$ & $\begin{array}{l}7 \cdot 8(3 \cdot 4) \\
7 \cdot 3(2 \cdot 9) \\
5 \cdot 5(1 \cdot 9)\end{array}$ & $\begin{array}{l}5.6(0.8) \\
6 \cdot 2(0.9) \\
6.5(0.8)\end{array}$ & $\begin{array}{l}6.2(0.5) \\
6.7(0.7) \\
6.7(0.8)\end{array}$ & $\begin{array}{l}7 \cdot 8(0 \cdot 7) \\
8 \cdot 1(0 \cdot 6) \\
8 \cdot 4(0 \cdot 8)\end{array}$ \\
\hline
\end{tabular}

${ }^{\star} \mathrm{p}<0.01$ compared with placebo.

Table 2 Haemodynamic function (mean (SEM)) at rest and during treadmill exercise at 1 mm ST segment depression

\begin{tabular}{|c|c|c|c|c|}
\hline & \multicolumn{2}{|l|}{ At rest } & \multicolumn{2}{|c|}{ At $1 \mathrm{~mm} S T$ segment depression } \\
\hline & $\begin{array}{l}\text { Heart } \\
\text { rate (beats/min) }\end{array}$ & $\begin{array}{l}\text { Rate } \\
\text { pressure product }\end{array}$ & $\begin{array}{l}\text { Heart } \\
\text { rate (beats/min) }\end{array}$ & $\begin{array}{l}\text { Rate } \\
\text { pressure product }\end{array}$ \\
\hline $\begin{array}{l}\text { Group } 1 \\
\text { Placebo } \\
\text { Nifedipine } \\
\text { Slow-release nifedipine }\end{array}$ & $\begin{array}{l}70(4) \\
73(5) \\
77(5)\end{array}$ & $\begin{array}{l}10170(2116) \\
10376(2261) \\
11207(1038)\end{array}$ & $\begin{array}{l}111(10) \\
114(9) \\
126(10)\end{array}$ & $\begin{array}{l}20838(1833) \\
21078(1998) \\
22139(1643)\end{array}$ \\
\hline $\begin{array}{l}\text { Group } 2 \\
\text { Placebo } \\
\text { Nifedipine } \\
\text { Slow-release nifedipine }\end{array}$ & $\begin{array}{l}50(1) \\
56(2) \\
56(2)\end{array}$ & $\begin{array}{l}6777(251) \\
7601(293) \\
7788(383)\end{array}$ & $\begin{array}{l}89(5) \\
91(5) \\
90(5)\end{array}$ & $\begin{array}{l}15427(1093) \\
16160(1260) \\
15917(1167)\end{array}$ \\
\hline
\end{tabular}




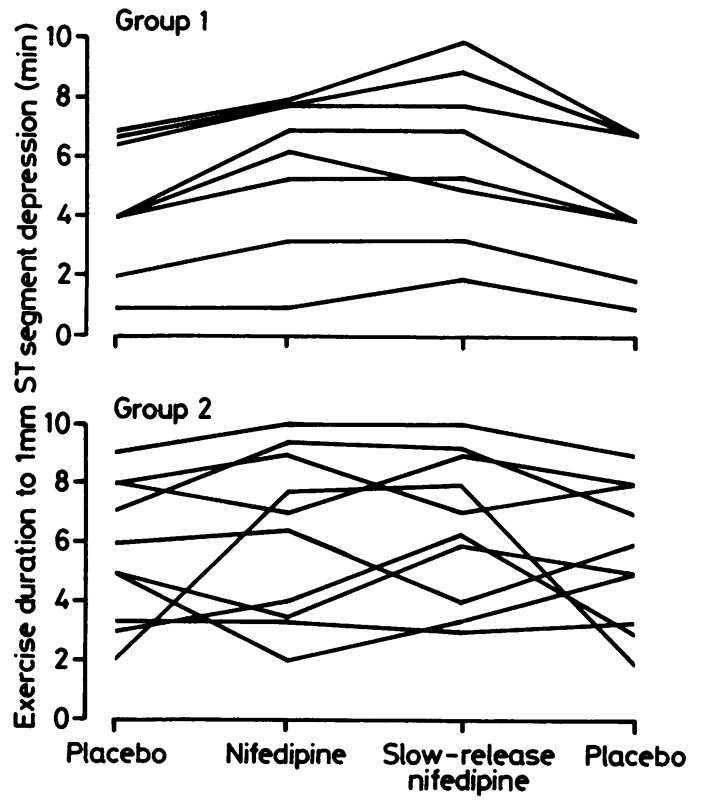

Figure Exercise duration to $1 \mathrm{~mm} S T$ segment depression during the placebo run in period and the two treatment periods in groups 1 and 2. Individual patient responses are shown.

and the placebo run in period but the differences were not significant (table 1). As in group 1, heart rate and rate pressure product at rest and at $1 \mathrm{~mm}$ ST segment depression were similar on the two preparations (table 2). When the results of exercise testing were examined in the group as a whole, addition of nifedipine or slow-release nifedipine to atenolol did not prolong the duration of exercise to $1 \mathrm{~mm}$ ST segment depression or to pain or the maximum exercise duration (table 1 and figure).

Individual patients responded differently to both nifedipine preparations. Addition of nifedipine to atenolol improved exercise duration to $1 \mathrm{~mm} \mathrm{ST}$ segment depression in six patients; no change occurred in one and there was a deterioration in three (figure). Addition of slow-release nifedipine to atenolol produced an improvement in exercise duration to $1 \mathrm{~mm}$ ST segment depression in six patients and a deterioration in three (figure). Four patients exercised for longer before the onset of ST segment depression on slow-release nifedipine than on nifedipine, two exercised for longer on nifedipine, and in four patients the exercise durations were similar on both preparations (figure).

Two patients complained of ankle oedema on nifedipine and one on slow-release nifedipine. Two patients experienced facial flushing and one transient lightheadedness after nifedipine.

\section{Discussion}

The patients in this study all had angina on effort and none gave a history of rest pain. This suggests that coronary flow limitation due to obstructive coronary artery disease was the cause of their symptoms rather than a change in vasomotor tone. Nifedipine is a calcium channel blocking agent with no important negative inotropic effects. ${ }^{5}$ It is a smooth muscle relaxant causing not only peripheral arteriolar dilatation but also coronary vasodilatation. ${ }^{6}$ Several studies have shown it to be an effective antianginal agent in patients with exertional angina, improving exercise haemodynamics and pain frequency both alone ${ }^{1}$ and in combination with a $\beta$ blocker. ${ }^{2}$ In one study a variable response to nifedipine was found; although some patients improved at a dose of $30 \mathrm{mg}$ a day they became worse at higher doses. ${ }^{1}$ To avoid this, all patients in this study were started on the lower dose of nifedipine or slow-release nifedipine and after three days the higher dose was given. All of our patients were able to continue on the higher dose.

Slow-release nifedipine is now being used to treat angina caused by obstructive coronary artery disease on the assumption that because the short acting preparation is effective a long acting preparation will be equally effective. This is not necessarily true and some preliminary unpublished data have suggested that slow-release nifedipine may not be effective in angina. Consequently, the manufacturers of the preparation have not been promoting its use in angina. The present study suggests that the slowrelease preparation is as effective as the short acting preparation in angina both alone and in combination with a $\beta$ blocker and that the blood concentrations obtained with the slow-release preparation are adequate.

Previous studies have shown a synergistic effect between nifedipine and a $\beta$ blocker. ${ }^{2}$ Theoretically, this would be expected since the detrimental effects of both drugs such as tachycardia induced by nifedipine will be prevented by the $\beta$ blocker and any increase in vascular resistance induced by the $\beta$ blocker will be overcome by nifedipine. Consequently, these two groups of drugs are widely used in combination. We therefore investigated the efficacy of slow-release nifedipine not only compared with nifedipine alone but also in combination with a $\beta$ blocker, atenolol. In this study the addition of nifedipine or slow-release nifedipine to atenolol produced no further benefit in the group as a whole in terms of angina frequency or exercise testing, though individual patients did improve-six with nifedipine and six with slow-release nifedipine. This is contrary to the findings of an earlier study in 
which the combination of nifedipine and propranolol was more effective than either drug alone. ${ }^{2}$ A possible explanation for the difference between our results with atenolol and those with propranolol may be due to the selectivity of the $\beta$ receptor blockade. Atenolol is a highly selective $\beta_{1}$ antagonist, whereas propranolol is a relatively non-selective $\beta$ receptor antagonist. Thus the undesirable effects of $\beta$ blockade, in particular the effects caused by $\beta_{2}$ receptor antagonism, such as a rise in peripheral or coronary vascular resistance, may have been less with atenolol than with propranolol and so any potential beneficial effects of a vasodilator may have been reduced. Findlay et al investigated the effects of nifedipine and atenolol both alone and in combination in the treatment of stable exertional angina pectoris and found that the combination was more effective than either drug alone when compared with placebo ${ }^{7}$ but they did not compare the combination with atenolol alone. A recent study in which the effects of verapamil, another calcium antagonist, and atenolol were compared both alone and in combination showed that the combination of the two drugs was more effective than either drug alone in improving exercise duration. ${ }^{8}$ Again this differs from our results and it may be because verapamil has greater negative inotropic effects than nifedipine. These will reduce myocardial work even further and hence energy and oxygen demands.

Though there was no difference between the preparations in the groups as a whole, individual patient responses were variable. Examination of these results shows that individual patients in both groups responded better to one preparation than the other in terms of exercise duration to $1 \mathrm{~mm}$ ST segment depression. This may reflect a similar phenomenon to that described previously in which a variation in the individual response to the short acting nifedipine was found. ${ }^{1}$ Thus if an unsatisfactory response is obtained in one patient it may be worthwhile trying the alternative preparation.
Slow-release nifedipine is an effective alternative to the more usual capsular preparation in the treatment of angina pectoris and could be used as the initial treatment in place of the capsular form alone or in combination with a $\beta$ blocker.

\section{References}

1 Deanfield J, Wright C, Fox K. Treatment of angina pectoris with nifedipine: the importance of dose titration. Br Med J 1983;286:1467-70.

2 Lynch P, Dargie H, Krikler S, Krikler D. Objective assessment of antianginal treatment: a double blind comparison of propranolol, nifedipine and their combination. Br Med J 1980;280:184-7.

3 Boneduce D, Canonico V, Mazza F, et al. Evaluation of the efficacy of slow-release nifedipine in systemic hypertension by ambulatory intra-arterial blood pressure monitoring. $J$ Cardiovasc Pharmacol 1985;7:145-51.

4 Zylber-Katz E, Koren G, Granit L, Levy M. Bioavailability of nifedipine. Comparison between two preparations. Biopharm Drug Dispos 1984;5:109-15.

5 Antman EM, Stone PH, Muller JE, Braunwald E. Calcium channel blocking agents in the treatment of cardiovascular disorders. Part 1 . basic and clinical electrophysiologic effects. Ann Intern Med 1980;93:875-85.

6 Fleckenstein A. Specific pharmacology of calcium in myocardium, cardiac pacemakers and vascular smooth muscle. Annu Rev Pharmacol Toxicol 1977;7:149-66.

7 Findlay IN, MacLeod K, Ford M, Gillen G, Elliott AT, Dargie HJ. Treatment of angina pectoris with nifedipine and atenolol: efficacy and effect on cardiac function. Br Heart $J$ 1986;55:240-5.

8 Findlay IN, MacLeod K, Gillen G, Elliott AT, Aitchison T, Dargie HJ. A double blind placebo controlled comparison of verapamil, atenolol, and their combination in patients with chronic stable angina pectoris. Br Heart J 1987;57:336-43. 